\title{
Temporal dependence of the selectivity property of SES stations in western Greece
}

\section{E. Dologlou}

Solid State Section, Department of Physics, University of Athens, Panepistimiopolis, Zografos 15784 Athens, Greece

Received: 13 February 2009 - Revised: 19 May 2009 - Accepted: 20 May 2009 - Published: 2 June 2009

\begin{abstract}
The selectivity property of the SES stations, IOA, PIR and PAT in western Greece, based on reported precursory SES signals and associated large earthquakes $\left(M_{w} \geq 5.4\right)$ that occurred from 1983 to the end of 2008, has been examined. Interesting temporal dependence of the sensitive ability of these stations has been unveiled. Physical mechanisms for the observed changes in selectivity might be related with tectonic and geodynamic events. For instance, selectivity for IOA exhibits a time dependence, for PAT probably is related to the activation of Wadati-Benioff zone while for PIR seems to be related to the specific tectonics of two confined areas such as the Cephalonia Transform Faulting zone in Ionian Sea and the southwestern part of the Hellenic Trench.
\end{abstract}

\section{Introduction}

The complexity of the tectonics and geodynamics in the broad Hellenic region renders Greece a rich natural laboratory for the study of numerous geophysical phenomena and earthquake precursors.

The interaction of three major tectonic plates, the Eurasian, the African and the Arabic and the rapid accumulation of stress, due to the rather high speed plate movements, is the main reason for the intensive seismicity of Greece, the highest in Europe. In the south, the convergence of the African and Eurasian plates forms an amphitheatric convex subduction zone (Hellenic Trench) extending from Zankythos island in the west to Rhodes island in the east (Fig. 1). As a result a Wadati-Benioff zone deeping at two different angles (around $15^{\circ}$ and $35^{\circ}$ ) into the mantle under the Aegean Sea is developed. Thrust mechanisms character-

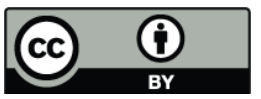

Correspondence to: E. Dologlou (edologl@phys.uoa.gr) ize the subduction zone while extensional stresses and normal faulting prevail in the mainland (McKenzie 1970, 1972, 1978). In the west, the collision of the Apulian subplate with the Eurasian is associated with compression causing orogenetic phenomena (mountains of NW Greece and Albania) and thrust faulting (Taymaz et al., 1990; Baker et al., 1997). These two compressional systems are linked by a confined zone of dextral strike slip faulting CFT (Cepfalonia Transform Faulting) offshore Cephalonia island (Fig. 1). In the east, the westward motion of central Turkey (Anatolia) relative to Eurasia, caused by the push of the Arabian plate, forms the North Anatolian Fault (NAF), the end of which, known as North Aegean Trough (NAT), penetrates into the Aegean Sea (Fig. 1) and probably projects under Hellenides (Karakaisis et al., 2004) to the Ionian Sea meeting the stike slip zone (CFT) of Chephalonia island at a triple junction (King et al., 1993). The Aegean microplate bounded in the north by the North Anatolian Trough and in the south by the Hellenic Trench moves southwestward (Fig. 1) relative to Eurasia (Le Pichon et al., 1995) at a velocity of (3035) $\mathrm{mm} / \mathrm{y}$ (McClusky et al., 2000). This tectonic mosaic is subjected to complicated dynamic stress interactions between its blocks which may affect not only the seismic behaviour but also the pre-seismic processes evolving in the region and thus, the related properties of different precursors (i.e. electromagnetic anomalies of low and high frequency, changes in the telluric field, etc.).

Low frequency $(<1 \mathrm{~Hz})$ transient changes of the Earth's telluric field, the so called Seismic Electric Signals (SES) have been detected by a telemetric network of VAN stations installed at different sites in Greece, throughout the last 27 years (Varotsos and Alexopoulos, 1984a, b; Varotsos et al., 1988, 2004).

A VAN station consists of several pairs of electrodes (dipoles), of different length $L$ (i.e. from some meters to a few $\mathrm{km}$ ) buried in the ground at different directions. The

Published by Copernicus Publications on behalf of the European Geosciences Union. 


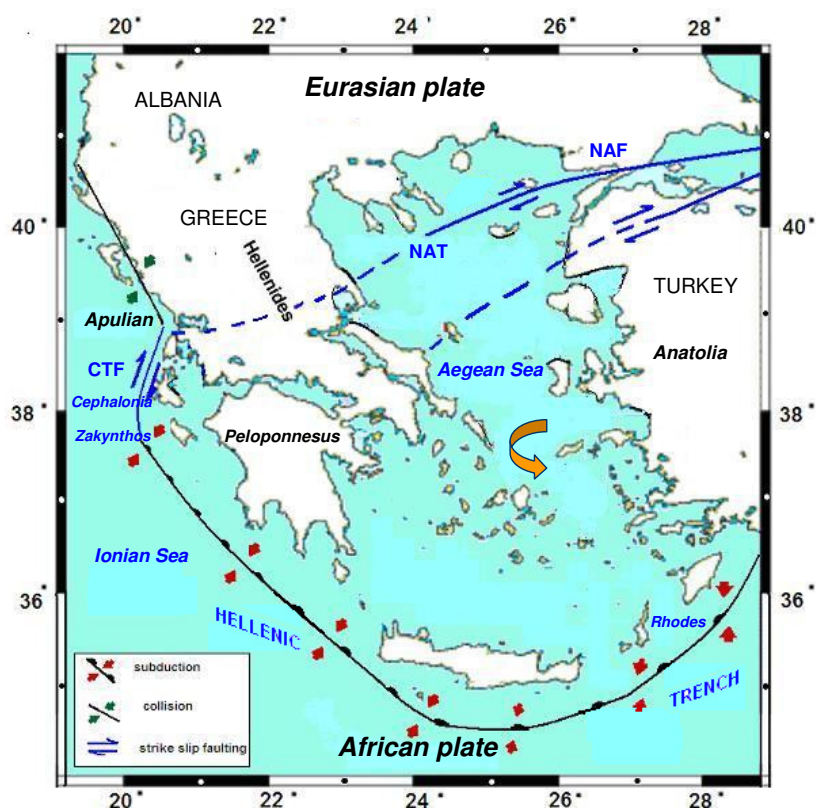

Fig. 1. Tectonic map of Greece.

discrimination of the SES signal from the noise is based on the $\Delta V / L$ criterion which means that at the same station and for the same direction, the potential difference $\Delta V$ between two electrodes per $L$ must be constant (Varotsos and Alexopoulos, 1984a; Varotsos et al., 1993, 2003). Recently the distinction became also possible by means of a new criteria based on the concept of "natural time" which considers the order evolution of events (i.e. 1st, 2nd, etc.) instead of the conventional time evolution (Varotsos et al., 2004 and references therein).

A brief description of the physical mechanism of the SES generation is as follows: before an earthquake, the tectonic stress (pressure) increases gradually in the candidate focal area and causes changes in various bulk physical properties e.g., conductivity (Varotsos, 1981), dielectric constant (Varotsos, 1978, 1980) etc. In addition some extrinsic properties also change including the relaxation time of impurity related electric dipoles in rock forming minerals. These dipoles consist of aliovalent impurities (Varotsos and Miliotis, 1974) and vacancies created for reasons of electrical neutrality (Varotsos and Mourikis, 1974; Kostopoulos et al., 1975). The relaxation time depends on both temperature and pressure (Varotsos, 1977; Varotsos, and Alexopoulos, 1981; Lazaridou et al., 1985) and under certain conditions becomes smaller with increasing stress (Varotsos et al., 1982). When the stress reaches a critical value the dipoles in the rocks in the preseismic volume, change orientation cooperatively and a transient current, which constitutes the SES signal, is emitted.

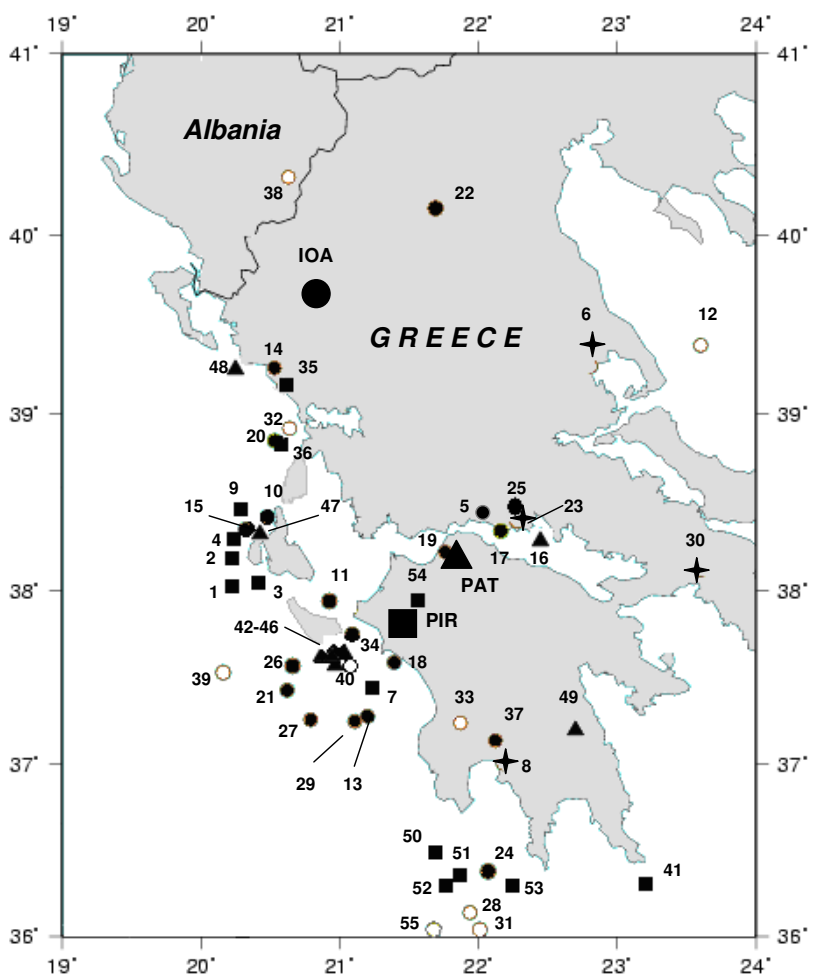

Fig. 2. The epicenters of all earthquakes listed and numbered in Table 1, denoted according to their detection SES station by small solid circles for IOA, small solid squares for PIR and small solid triangles for PAT station. Crosses refer to events detected by other SES stations and open circles to events without reported SES. Large solid circles, squares and triangles show the position of IOA, PIR and PAT stations in W. Greece, respectively.

One of the most important characteristics of the SES signal is the selectivity which significantly contributed to the determination of the epicentre of impending earthquakes. The selectivity states that a VAN station can be sensitive to the SES from some specific seismic areas while remains insensitive to SES from some others even at closer distances. A tentative physical explanation of this property is as follows assuming (Sarlis et al., 1999) that the SES signal is emitted from a source inside the pre focal area: If a conductive path (i.e. fault, conductive rock channel) exists between the source and a site on the earth's surface, the SES signal will travel through it to reach the site. Thus, laborious and time consuming experiments of testing at different local sites are needed to pick up a sensitive VAN station (e.g., Kondo et al., 2002).

Among the VAN stations, three of them IOA, PIR and PAT (Fig. 2) can "see" the seismicity of Western Greece while other stations as ASS, VOL, LAM, KER located in the northern and central mainland are sensitive to northern or central Greece and Aegean sea (Varotsos and Alexopoulos, 1987; Varotsos et al., 2003, 2005a, b, 2006a, b). The main mountain chain of Hellenides extended in a NNW-SSE direction 
(Fig. 1) seems to act as a natural barrier for the propagation of SES signals. Thus, all precursory SES of earthquakes that occurred in Western Greece have been detected at the stations lying west of Hellenides, namely IOA, PIR and PAT. Relationships between earthquake parameters and associated precursory SES properties have been reported in various articles (e.g., Uyeda et al., 1999; Dologlou, 2008a, b). Dologlou (2008b) examined whether a SES station showed any preference at predicting earthquakes of a specific focal mechanism ( strike -slip, normal or thrust type) by using large earthquakes $(M>5)$ and precursory SES for the period 1995-2007, in western Greece and compared with the results for 1983-1994 (Uyeda et al., 1999). Furthermore, the operation of the VAN network for almost three decades showed that the detection ability of those stations switched in time from PIR to IOA and vice versa (Uyeda et al., 1999; Dologlou, 2008b and references therein). In another paper Dologlou (2008a) a possible existence of a correlation between the stress drop of an earthquake and the lead time (which is the time difference between the detection of SES and the occurrence of the impending earthquake) of the associated SES was investigated. A power law relation was found which was strengthened through new data in a later article (Dologlou, 2009).

In the present work, we mainly focus on the changes of the selectivity of SES stations during the last three decades in western Greece. Here, we attempt for the first time to forward possible explanations for the changes with the aid of tectonics and geodynamics. In addition, since the last two years (2007 to 2008) a number of large earthquakes occurred in Greece, we re examine the degree of dependence of the SES selectivity property on the earthquake mechanism type and compare the results with previous findings.

\section{Data and analysis}

In this study we refer to all earthquakes with magnitude $M_{w} \geq 5.4$, taken from PDE-USGS catalogue, that occurred in the area $(19-24)^{\circ} \mathrm{E},(36-41)^{\circ} \mathrm{N}$ during the period $1 / 1 / 1983$ to $31 / 12 / 2008$ and to their associated reported precursory SES signals (Varotsos, 2005; Varotsos et al., 2005a, b, 2007, 2008; Sarlis et al., 2008). There were 55 such events as listed in a chronological order in Table 1 along with their dates, epicentres, depths, moment magnitudes and SES detection stations. All earthquake epicentres, numbered as shown in Table 1, are presented in Fig. 2 by small solid circles, squares or triangles according to their SES detection station. Among them, fourteen events (small solid squares) were preceded by SES at PIR, nineteen (small solid circles) at IOA and nine (small solid triangles) at PAT stations. Four events (no. 6, 8, 23 and 30) denoted by a cross were recorded at ASS, KER, VOL and LAM, respectively. For the remaining nine events (open circles) no SES was reported. Our interest is focused on those earthquakes that were preceded by a SES at IOA,
PIR or PAT stations (Fig. 2) which are sensitive to W. Greece. The IOA station, operating since 1982, is equipped with short (i.e. $L$ of the order of $100 \mathrm{~m}$ ) and long (i.e. $L$ of the order of $\mathrm{km}$ ) dipoles array and is situated close to Ioannina city in NW Greece. The PIR station, installed in 1982 in W. Peloponnesus, has been moved by $5 \mathrm{~km}$ from its previous site since 1993 and is currently operating with long dipoles only (Varotsos et al., 2006c). Finally, the PAT station, in N. Peloponnesus, has been moved $20 \mathrm{~km}$ from its previous position since 1992 (Varotsos, 2005).

In an effort to examine the possible dependence of SES selectivity on the earthquake mechanism, fault plane centroid moment solutions, CMT-Harvard, (http://neic.usgs.gov/neis/ sopar/) are given in Fig. 3a, b and c. Table 2 presents the distribution of events of Table 1 according to their main mechanism (strike-slip, thrust and normal) type and their SES detection station. For some events there is a varying degree of thrust or normal component in the main strike-slip mechanism which is denoted by one or two asterisks, respectively.

\section{Discussion}

It will be interesting to investigate whether the complicated tectonics and geodynamics that prevail in the region of Greece affect the selectivity property of the SES stations. Concerning the tectonics, it seems from Fig. 3a that all of events (no. 1, 2, 3, 4, 9), which occurred within the narrow CFT zone of strike-lip faulting offshore Chephalonia (Fig. 1) and preceded by an SES recoded at PIR station, were indeed strike-slip type. The other two thrust type events (no. 10 and 15) detected by IOA (Fig. 3b) occurred east of CFT zone. Actually the NOA (National Observatory of Athens,) catalogue (http://www.gein.noa.gr/) gives for event no. 15 an epicentre $(38.28 \mathrm{~N}-20.41 \mathrm{E})$ lying east of the reported by USGS one and according to Roumelioti et al. (2004) falling outside the CFT zone while for event no. 10 both (NOA and USGS) epicentres have the same longitude. Thus, the cause of the difference in source mechanism before and after 1987 in the broad area, seems to be related to the epicentre location and not to a temporal change as mentioned in a previous paper by Uyeda et al. (1999).

In 2008, the segment of the Hellenic Trench (HT) S. W. of Peloponnesus (Fig. 1), became active. We may suggest this activation if we compare the shallow seismicity (depth $<40 \mathrm{~km}$ ) in that region before and after 2008. From Table 1 we observe that during 25 years (1983-2007) only one shallow earthquake with $M>6$ (event no. 24) occurred while during 2008 three events (no. 50, 51, 52) with $M>6$, one of which was the strongest earthquake $(M=6.9)$ of the last two decades, took place (Fig. 3c). PIR station responded also to this area since it detected all precursory SES for these earthquakes. 

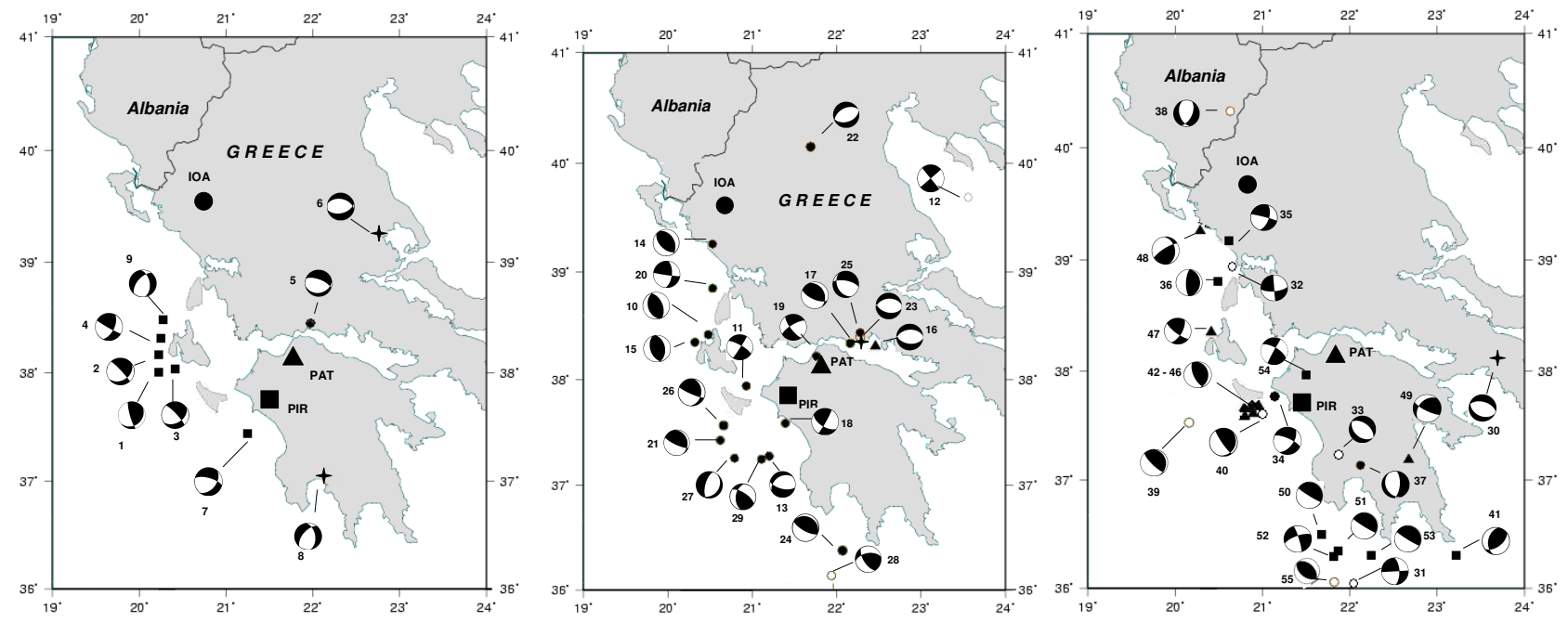

Fig. 3. CMT fault plane solutions for the earthquakes listed in Table 1 for three different periods. (a) 1983-1987, (b) 1988-1998 and (c) 1999-2008. A lower hemisphere projection is used with black and white quadrants for compression and dilatation respectively. Numbers attached refer to the events in Table 1. Small solid circles, squares and triangles mark the epicenters of earthquakes preceded by SES at IOA, PIR and PAT stations, respectively while crosses refer to events detected by other stations and open circles to events without reported SES. Large solid circles, squares and triangles show the position of IOA, PIR and PAT stations.

On the other hand, neither IOA nor PAT selection ability seems to be related to any specific tectonic area. IOA covers the very broad area of Ionian Sea and continental W. Greece (Fig. 3b) while for PAT the selectivity space pattern appears scattered (Fig. 3c).

Let us now examine the geodynamics that prevailed and probably affected many physical processes, including precursory phenomena and seismicity, in the area of Greece during the last almost three decades. Two significant dynamic episodes took place during this time in the broader region. The first, was the jolt of the western end of North Anatolian Fault (NAF in Fig. 1) on 17 August 1999, that caused the $M_{w}=7.4$ Izmit, Turkey destructive earthquake, which according to Brodsky et al., 2000, triggered widespread regional seismicity in Greece at a distance of $400-1000 \mathrm{~km}$ from epicentre. Transient stresses transported from the main shock could have been responsible for the enhanced seismicity which culminated in the Athens damaging event (no. 30) on 7 September 1999. The second episode was the activation of the western part of the Hellenic Wadati-Benioff zone that according to our opinion began just after the $M_{w}=6.7$ earthquake (no. 41) which occurred on 6 January 2006 at a depth of $66 \mathrm{~km}$, inside the slab under Peloponnesus of the WadatiBenioff zone of the Hellenic Trench. This earthquake seems to have triggered deep seismicity in this area (i.e. event no. 49 and some others of smaller magnitudes $M_{w}<5.4$ ).

The argument stands for the possibility that these two dynamic episodes might have affected the selective ability of the SES stations under study. From Table 1, three periods (1983-1987, 1988-1998 and 1999-2008) during which only one or two stations were active, can be recognized. From
1983 to the end of 1987, PIR station dominated (Fig. 3a). On the contrary, from 1988 till the end of 1998, IOA became almost the only sensitive station to the seismicity in western Greece (Fig. 3b) while PIR ceased to be sensitive. At last, from 1999 to 2008 (Fig. 3c), the detection of the majority of the earthquakes that occurred in this area was shared between PIR and PAT stations while only two events (no. 34, 37) were preceded by a SES at IOA (Fig. 3c).

The origin of this temporal selective behaviour is quite unclear. However, we will attempt to relate it to the dynamic episodes mentioned above. A factor that might influence the selective ability of a SES station through time could be a change in the direction of the predominant principal dynamic stresses in a region which according to Press and Allen (1995) may be introduced by small changes in the direction of plate movements as already mentioned by Uyeda et al. (1999). On the other hand the detection ability of a station in some cases might be only space dependent and in some others might be affected by both space and time.

During the first period 1983-1987, when PIR station was recording SES activity, the seismic activity in $\mathrm{W}$. Greece was mostly clustered in the narrow CFT zone (Fig. 3a). The next large strike slip-type earthquake $\left(M_{w}>5.4\right)$ that occurred in this zone was the event (no. 47) which was detected at PAT in 2007 (Fig. 3c).

During the next time period 1988-1998, no large $\left(M_{w}>5.4\right)$ earthquake occurred inside the CFT zone and the southwestern Hellenic Trench (HT) segment (Fig. 1), which are the two sensitive areas to PIR, (Fig. 3b). Consequently no SES with significant amplitude was detected at PIR station (recall that event no. 15, having a thrust mechanism and 
Table 1. All earthquakes with magnitude $M_{w} \geq 5.4$ in the area $(19-24)^{\circ} \mathrm{E},(36-41)^{\circ} \mathrm{N}$ and corresponding SES stations for the period 1 January 1983 to 31 December 2008.

\begin{tabular}{|c|c|c|c|c|c|c|c|c|c|}
\hline no & Date & $\begin{array}{l}\mathrm{H} \\
(\mathrm{GMT})\end{array}$ & Min & $\mathrm{Sec}$ & Lat & Long & $\begin{array}{l}\text { Depth } \\
(\mathrm{km})\end{array}$ & $M_{w}$ & $\begin{array}{l}\text { SES } \\
\text { station }\end{array}$ \\
\hline 1 & 830117 & 12 & 41 & 29.7 & 38.03 & 20.23 & 14 & 6.8 & PIR \\
\hline 2 & 830119 & 0 & 2 & 13.69 & 38.17 & 20.23 & 18 & 5.8 & PIR \\
\hline 3 & 830131 & 15 & 27 & 0 & 38.11 & 20.3 & 27 & 5.4 & PIR \\
\hline 4 & 830323 & 23 & 51 & 6.51 & 38.29 & 20.26 & 19 & 6.4 & PIR \\
\hline 5 & 840211 & 8 & 2 & 51.5 & 38.4 & 22.09 & 28 & 5.6 & IOA \\
\hline 6 & 850430 & 18 & 14 & 12.71 & 39.27 & 22.81 & 26 & 5.6 & ASS \\
\hline 7 & 850907 & 10 & 20 & 50.21 & 37.44 & 21.24 & 31 & 5.4 & PIR \\
\hline 8 & 860913 & 17 & 24 & 31.49 & 37.01 & 22.18 & 11 & 5.8 & KER \\
\hline 9 & 870227 & 23 & 34 & 52.03 & 38.47 & 20.29 & 5 & 5.7 & PIR \\
\hline 10 & 880518 & 5 & 17 & 42.55 & 38.42 & 20.48 & 26 & 5.5 & IOA \\
\hline 11 & 881016 & 12 & 34 & 5.66 & 37.94 & 20.93 & 25 & 5.9 & IOA \\
\hline 12 & 890319 & 5 & 36 & 58.94 & 39.25 & 23.52 & 10 & 5.4 & \\
\hline 13 & 890820 & 18 & 32 & 29.91 & 37.28 & 21.2 & 10 & 5.8 & IOA \\
\hline 14 & 900616 & 2 & 16 & 21.12 & 39.26 & 20.53 & 31 & 5.6 & IOA \\
\hline 15 & 920123 & 4 & 24 & 15.65 & 38.35 & 20.32 & 16 & 5.6 & IOA \\
\hline 16 & 921118 & 21 & 10 & 41.49 & 38.31 & 22.45 & 14 & 5.9 & PAT \\
\hline 17 & 930318 & 15 & 47 & 0.42 & 38.34 & 22.16 & 59 & 5.8 & IOA \\
\hline 18 & 930326 & 11 & 58 & 15.17 & 37.59 & 21.39 & 10 & 5.4 & IOA \\
\hline 19 & 930714 & 12 & 31 & 49.44 & 38.22 & 21.76 & 22 & 5.6 & IOA \\
\hline 20 & 940225 & 2 & 30 & 51.59 & 38.85 & 20.53 & 35 & 5.4 & IOA \\
\hline 21 & 940416 & 23 & 9 & 33.99 & 37.43 & 20.62 & 26 & 5.5 & IOA \\
\hline 22 & 950513 & 8 & 47 & 12.73 & 40.15 & 21.69 & 14 & 6.6 & IOA \\
\hline 23 & 950615 & 0 & 15 & 48.73 & 38.4 & 22.28 & 14 & 6.5 & VOL \\
\hline 24 & 971013 & 13 & 39 & 37.49 & 36.38 & 22.07 & 24 & 6.4 & IOA \\
\hline 25 & 971105 & 21 & 10 & 28.68 & 38.44 & 22.28 & 23 & 5.6 & IOA \\
\hline 26 & 971118 & 13 & 7 & 41.73 & 37.57 & 20.66 & 33 & 6.6 & IOA \\
\hline 27 & 980110 & 19 & 21 & 56.51 & 37.26 & 20.79 & 33 & 5.5 & IOA \\
\hline 28 & 980429 & 3 & 30 & 39.34 & 36.14 & 21.94 & 33 & 5.5 & \\
\hline 29 & 981006 & 12 & 27 & 41.97 & 37.25 & 21.11 & 10 & 5.4 & IOA \\
\hline 30 & 990907 & 11 & 56 & 49.38 & 38.12 & 23.6 & 10 & 6.0 & LAM \\
\hline 31 & 000524 & 5 & 40 & 37.74 & 36.04 & 22.01 & 33 & 5.7 & \\
\hline 32 & 000526 & 1 & 28 & 22.54 & 38.92 & 20.64 & 0 & 5.6 & \\
\hline 33 & 010916 & 2 & 0 & 47.39 & 37.24 & 21.87 & 10 & 5.5 & \\
\hline 34 & 021202 & 4 & 58 & 55.19 & 37.75 & 21.09 & 10 & 5.7 & IOA \\
\hline 35 & 030814 & 5 & 14 & 54.76 & 39.16 & 20.6 & 10 & 6.3 & PIR \\
\hline 36 & 030814 & 16 & 18 & 2.45 & 38.83 & 20.57 & 10 & 5.5 & PIR \\
\hline 37 & 040301 & 0 & 35 & 58.05 & 37.14 & 22.12 & 9 & 5.6 & IOA \\
\hline 38 & 041123 & 2 & 26 & 16.35 & 40.32 & 20.63 & 15 & 5.5 & \\
\hline 39 & 050131 & 1 & 5 & 33.56 & 37.53 & 20.16 & 31 & 5.7 & \\
\hline 40 & 051018 & 15 & 26 & 0.26 & 37.62 & 20.92 & 14 & 5.7 & \\
\hline 41 & 060108 & 11 & 34 & 55.64 & 36.31 & 23.21 & 66 & 6.7 & PIR \\
\hline 42 & 060404 & 22 & 5 & 5.08 & 37.64 & 20.96 & 16 & 5.5 & PAT \\
\hline 43 & 060411 & 0 & 2 & 41.5 & 37.64 & 20.92 & 18 & 5.5 & PAT \\
\hline 44 & 060411 & 17 & 29 & 28.4 & 37.68 & 20.91 & 18 & 5.5 & PAT \\
\hline 45 & 060412 & 16 & 52 & 1.2 & 37.61 & 20.95 & 19 & 5.7 & PAT \\
\hline 46 & 060419 & 15 & 16 & 24.6 & 37.66 & 20.93 & 19 & 5.4 & PAT \\
\hline 47 & 070325 & 13 & 57 & 58.2 & 38.34 & 20.42 & 15 & 5.7 & PAT \\
\hline 48 & 070629 & 18 & 9 & 11.22 & 39.27 & 20.26 & 10 & 5.4 & PAT \\
\hline 49 & 080106 & 5 & 14 & 20.18 & 37.22 & 22.69 & 75 & 6.2 & PAT \\
\hline 50 & 080214 & 10 & 9 & 22.72 & 36.5 & 21.67 & 29 & 6.9 & PIR \\
\hline 51 & 080214 & 12 & 8 & 55.79 & 36.35 & 21.86 & 28 & 6.5 & PIR \\
\hline 52 & 080220 & 18 & 27 & 6 & 36.29 & 21.77 & 9 & 6.2 & PIR \\
\hline 53 & 080510 & 20 & 53 & 4.2 & 36.3 & 22.24 & 57 & 5.4 & PIR \\
\hline 54 & 080608 & 12 & 25 & 29.71 & 37.96 & 21.52 & 16 & 6.3 & PIR \\
\hline 55 & 080621 & 11 & 36 & 23.9 & 36.06 & 21.82 & 5 & 5.6 & \\
\hline
\end{tabular}


Table 2. The distribution of events of Table 1 according to their main mechanism type and detection station. Thrust or normal component in the main strike-slip mechanism is denoted by one or two asterisks, respectively.

\begin{tabular}{llll}
\hline SES station & Strike-slip & Thrust & Normal \\
\hline PIR & $1^{*}, 2^{*}, 3,4,7^{* *}, 9^{* *}, 35,41,52,54$ & $36,50,51,53$ & \\
IOA & $11,18,19,20,26^{*}, 29^{*}, 34$ & $10,14,15,17,21,24$ & $5,13,22,25,27,37$ \\
PAT & $47,48,49^{*}$ & $42,43,44,45,46$ & 16 \\
\hline
\end{tabular}

a alternative epicentre by NOA shifted to the east, should not belong to this zone). IOA became the master station which detected SES of most of earthquakes in either the inner side of the Hellenic Trench or in the mainland without any clear space pattern. We note that the correlation of event 24 to a SES detected by IOA might be questionable since the distance between the earthquake epicentre and the SES station is quite large. In 1999, the activation of the North Anatolian Fault (NAF) first caused the Izmit earthquake and might have triggered the destructive Athens event (no. 30) which was preceded by a SES at LAM station, Central Greece (Fig. 3b). Thus, the sensitive period (1988-1998) for IOA station ended before the first dynamic episode that might have transferred significant stress in the Greek regime which might have altered the geodynamics, i.e., the interactions and the relative motions between the tectonic blocks in this highly fragmented region. According to Press and Allen (1995), this could yield a change in the direction of predominant stresses which would reflect a change in the direction of the emitted SES vector (see p. 143, Varotsos, 2005). As a result, the SES signal might be detected at a different site.

During the last period 1999-2008, the above mentioned new geodynamical status introduced by Izmit earthquake might have influenced the selective behaviour of SES stations. IOA, as mentioned, almost stopped SES detections (Fig. 3c). On the other hand, the southwestern part of the Hellenic Trench, the second PIR "preferred" area, became seismically active (Fig. 3c) and PIR regained its detectability. It is possible that tectonics affected both seismicity and station sensitivity.

At last, at the beginning of 2006, the activation of the Wadati-Benioff zone might have triggered PAT station of which detection ability began just after the $M_{w}=6.7$ earthquake (no. 41) that occurred on 6 January 2006 at a depth of $66 \mathrm{~km}$ inside the slab sinking under Peloponnesus. It can be only a hint that the sensitivity of PAT station might be related to this second dynamic episode.

Finally, based on data from the period 1983-2008, we reexamined the dependence of the SES selectivity on earthquake mechanism type. The results summarized in Table 2 do not reveal any systematic relation for IOA station which seems to detect events of all types while PIR and PAT exhibit a preference to strike slip and thrust type events. We believe that this behaviour of PIR depends on the earthquake location i.e., whether the epicentre belongs to the CFT zone or the S. W. Hellenic Trench. Thus, from 1983-1987 when the strike slip faulting CFT zone became active, PIR detected strike-slip events (as it is also reported by Uyeda et al., 1999) while in 2008 it switched to thrust type since the southwestern part of the thrust faulting subduction zone in the Hellenic Trench has been activated.

\section{Conclusions}

Here, we attempt to interrelate tectonics and geodynamical changes in the Hellenic region with observed changes in the selectivity of SES stations. The selective behaviour of the SES stations in W. Greece, for the last almost three decades, unveiled a temporal dependence. For instance, IOA covering a broad area in western Greece, seems to exhibit a time dependence. The activation of North Anatolian Fault (NAF) that caused the Izmit earthquake, on 17 August 1999, coincided with the observed change in the selectivity of IOA station which remained almost inactive after this dynamic episode. This major event might have produced a westward stress transfer to alter the geodynamical status in Greece and probably affected the direction of dominating stresses and consequently the sensitivity of IOA station. In 2006, another dynamic episode, i.e., the activation of subduction under Peloponnesus segment of the Wadati-Benioff zone in the Hellenic Trench took place and at the same time the detectability of PAT station mainly started. The origin of this behaviour may be understood by more data accumulation in the future. Furthermore, PIR selectivity seems to be related to two confined areas with characteristic tectonics, i.e., the CFT strike-slip faulting zone and the southwestern part of the Hellenic Trench (HT).

At last, based on new data (September 2007 to the end of 2008), the dependence of the selectivity of the SES stations in western Greece on earthquake mechanism has been revisited and no systematic relation was found for IOA station while PIR and PAT show a preference to detect events of strike slip and thrust type.

Edited by: M. E. Contadakis

Reviewed by: T. Nagao, S. Uyeda, and another anonymous referee 


\section{References}

Baker, C., Hatzfeld, D., Lyon-Caen, H., Papadimitriou, E., and Rigo, A.: Earthquake mechanisms of the Adriatic Sea and Western Greece: implications for the oceanic subduction-continental collision transition, Geophys. J. Int., 131, 559-594, 1997.

Brodsky, E., Karakostas, V., and Kanamori, H.: A new observation of dynamically triggered regional seismicity: earthquakes in Greece following the August, 1999, Izmit, Turkey earthquake, Geophys. Res. Lett., 27, 2741-2744, 2000.

Dologlou, E.: Possible relationship between Seismic Electric Signals (SES) lead time and earthquake stress drop, Proc. Jpn. Acad. Ser. B, 84, 117-122, 2008a.

Dologlou, E.: Some Relationships between VAN Seismic Electric Signals (SES) lead time and Earthquake Parameters: Study for the 1995-2007 Period, Acta Geophys., 56(4), 1015-1024, 2008b.

Dologlou, E.: Power law relationship between parameters of earthquakes and precursory electrical phenomena revisited, Nat. Hazards Earth Syst. Sci., 9, 17-23, 2009,

http://www.nat-hazards-earth-syst-sci.net/9/17/2009/.

Karakaisis, G. F., Papazachos, C. B., Scordilis, E. M., and Papazachos, B. C.: Current accelerating seismic excitation along the northern boundary of the Aegean microplate, Tectonophysics, 383, 81-89, 2004.

King, G., Sturdy, D., and Whitney, J.: Landscape geometry and active tectonics of northwest Greece, Geol. Soc. Am. B., 105, 137-161, 1993.

Kondo, S., Uyeda, S., and Nagao, T.: The selectivity of the Ioannina VAN station, J. Geodyn., 33, 433-461, 2002.

Kostopoulos, D., Varotsos, P., and Mourikis, S.: Conductivity of crystalline NaI, Can. J. Phys., 53, 1318-1320, 1975.

Lazaridou, M., Varotsos, C., Alexopoulos, K., and Varotsos, P.: Point defect parameters of LiF, J. Phys. C: Solid State Physics, 18, 3891-3895, 1985.

Le Pichon, X., Chamot-Rooke, N., Lallemant, S., Noomen, R., and Veis, G.: Geodetic determination of the kinematics of central Greece with respect to Europe: Implications for eastern Mediterranean tectonics, J. Geophys. Res., 100, 12675-12690, 1995.

McClusky, S., Balassanian, S., and Barka, A., et al. (28 authors): GPS constraints on plate motions and deformations in the eastern Mediterranean: implications for plate dynamics, J. Geophys. Res., 105, 5695-5719, 2000.

McKenzie, D. P.: The plate tectonics of the Mediterranean region, Nature, 226, 239-243, 1970.

McKenzie, D.: Active tectonics of the Mediterranean region, Geophys. J. R. Astr. Soc., 30, 109-185, 1972.

McKenzie, D.: Active tectonics of the Alpine - Himalayan belt: the Aegean Sea and surrounding regions, Geophys. J. R. Astr. Soc., 55, 217-254, 1978.

Press, F. and Allen, C.: Patterns of seismic release in the southern California region, J. Geophys. Res., 100, 6421-6430, 1995.

Roumelioti, Z., Benetatos, C., Kiratzi, A., Stavrakakis, G., and Melis, N.: A study of the 2 December 2002 (M5.5) Vartholomio (western Peloponnese, Greece) earthquake and of its largest aftershocks, Tectonophysics, 387, 65-79, 2004.

Sarlis, N., Lazaridou, M., Kapiris, P., and Varotsos, P.: Numerical model of the selectivity effect and the $\Delta V / L$ criterion, Geophys. Res. Lett., 26, 3245-3248, 1999.

Sarlis, N., Skordas, E., Lazaridou, M., and Varotsos, P.: Investi- gation of the seismicity after the initiation of a Seismic Electric Signal activity until the main shock, Proc. Japan Acad. Ser. B, 84, 331-343, 2008.

Taymaz, T., Jackson, J. A., and Westaway, R.: Earthquake mechanisms in the Hellenic Trench near Crete, Geophys. J. Int., 102, 695-731, 1990.

Varotsos, P. A.: On the temperature and pressure dependence of the defect formation volume in ionic crystals, J. Phys. (France) Lettr., 38, L455-L458, 1977.

Varotsos, P. A.: An estimate of the pressure dependence of the dielectric constant in alkali halides, Phys. Status Solidi B, 90, 339343, 1978.

Varotsos, P.: Determination of the dielectric constant of alkali halide mixed crystals, Phys. Status Solidi B, 100, K133-K138, 1980.

Varotsos, P.: Determination of the composition of the maximum conductivity or diffusivity in mixed alkali halides, J. Phys. Chem. Solids, 42, 405-407, 1981.

Varotsos, P. A.: The Physics of Seismic Electric Signals, TerraPub, Tokyo, 2005.

Varotsos, P. A. and Mourikis, S.: Difference in conductivity between LiD and LiH crystals, Phys. Rev. B, 10, 5220-5224, 1974.

Varotsos, P. and Miliotis, D.: New aspects on the dielectric properties of the alkali halides with divalent impurities, J. Phys. Chem. Solids, 35, 927-930, 1974.

Varotsos, P. and Alexopoulos, K. : Migration entropy for the bound fluorine motion in alkaline earth fluorides, J. Phys. Chem. Solids, 41, 443-446, 1980a.

Varotsos, P. and Alexopoulos, K.: Negative activation volumes of defects in solids, Phys. Rev. B, 21, 4898-4899, 1980b.

Varotsos, P. and Alexopoulos, K.: Migration parameters for the bound fluorine motion in alkaline earth fluorides II, J. Phys. Chem. Solids, 42, 409-410, 1981.

Varotsos, P. and Alexopoulos, K.: Physical properties of the variations of the electric field of the earth preceding earthquakes I, Tectonophysics, 110, 73-98, 1984a.

Varotsos, P. and Alexopoulos, K.: Physical properties of the variations of the electric field of the earth preceding earthquakes, II. Determination of epicentre and magnitude, Tectonophysics, 110, 99-125, 1984b.

Varotsos, P. and Alexopoulos, K.: Physical properties of the variations in the electric field of the earth preceding earthquakes, III, Tectonophysics, 136, 335-339, 1987.

Varotsos, P., Alexopoulos, K., and Nomicos, K.: Comments on the pressure variation of the Gibbs energy for bound and unbound defects, Phys. Status Soldi B, 111, 581-590, 1982.

Varotsos, P., Alexopoulos, K., Nomicos,K., and Lazaridou M.: Official earthquake prediction procedure in Greece, Tectonophysics, 152, 193-196, 1988.

Varotsos, P., Alexopoulos, K., and Lazaridou M.: Latest aspects of earthquake earthquake prediction in Greece based on Seismic Electric Signals II, Tectonophysics, 224, 1-37, 1993.

Varotsos, P., Sarlis, N., and Skordas, E.: Electric fields that "arrive" before the time-derivative of the magnetic field prior to major earthquakes, Phys. Rev. Lett., 91, 148501, doi:10.1103/PhysRevLett.91.148501, 2003.

Varotsos, P., Sarlis, N., and Skordas, E.: Seismic Electric Signals and 1/f noise in natural time, e-print arXiv:condmat/0711.3766v1, 23 November 2007.

Varotsos, P., Sarlis, N., and Skordas, E.: Seismic Electric 
Signals and 1/f noise in natural time, e-print arXiv:condmat/0711.3766v3, 1 February 2008.

Varotsos, P. A., Sarlis, N. V., Skordas, E. S., and Lazaridou, M. S.: Entropy in the natural time-domain, Phys. Rev. E., 70, 011106, doi:10.1103/PhysRevE.70.011106, 2004.

Varotsos, P. A., Sarlis, N. V., Tanaka, H. K., and Skordas, E. S.: Some properties of the entropy in the natural time, Phys. Rev. E., 71, 032102, doi: 10.1103/Phys- RevE.71.032102, 2005a

Varotsos, P. A., Sarlis, N. V., Tanaka, H. K., and Skordas, E. S.: Similarity of fluctuations in correlated systems, The case of seismicity, Phys. Rev. E., 72, 041103, doi:10.1103/PhysRevE.72.041103, 2005b

Varotsos, P. A., Sarlis, N. V., Skordas, E. S., Tanaka, H. K., and Lazaridou, M. S.: Entropy of seismic electric signals: Analysis in natural time under time reversal, Phys. Rev. E, 73, 031114, doi:10.1103/PhysRevE.73.031114, 2006a.
Varotsos, P. A., Sarlis, N. V., Skordas, E. S., Tanaka, H. K., and Lazaridou, M. S.: Attempt to distinguish longrange temporal correlations from the statistics of the increments by natural time analysis, Phys. Rev. E., 74, 021123, doi:10.1103/PhysRevE.74.021123, 2006b.

Varotsos, P., Sarlis, N., Skordas, E., and Lazaridou, M.: Additional evidence on some relationship between Seismic Electric Signals (SES) and earthquake focal mechanism, Tectonophysics, 412, 279-288, 2006c.

Uyeda, S., Khaled Al-Damegh, S., Dologlou, E., and Nagao T.: Some relationship between VAN seismic electric signals (SES) and earthquake parameters, Tectonophysics, 304, 41-55, 1999. 